\title{
Comparison of ASR Mitigation Methodologies
}

\author{
Mohammad S. Islam ${ }^{1,2), *}$
}

(Received December 17, 2013, Accepted May 22, 2014)

\begin{abstract}
This study evaluates the dosages of Class F fly ash, lithium nitrate and their combinations to suppress the excessive expansion caused by alkali-silica reactivity (ASR). In order to serve the proposed objective, the mortar bar specimens were prepared from (1) four dosages of Class F fly ash, such as 15, 20, 25 and $30 \%$ as a partial replacement of Portland cement, (2) up to six dosages of lithium nitrate, such as lithium-to-alkali molar ratios of $0.59,0.74,0.89,1.04,1.19$ and 1.33 , and (3) the combination of lithium salt (lithium-to-alkali molar ratio of 0.74$)$ and two dosages of Class F fly ash (15 and $20 \%$ as a partial replacement of Portland cement). Percent contribution to ASR-induced expansion due to the fly ash or lithium content, test duration and their interaction was also evaluated. The results showed that the ASR-induced expansion decreased with an increase in the admixtures in the mortar bar. However, the specimens made with the both Class F fly ash and lithium salt produced more effective mitigation approach when compared to those prepared with fly ash or lithium salt alone. The ASR-induced expansions of fly ash or lithium bearing mortar bars by the proposed models generated a good correlation with those obtained by the experimental procedures.
\end{abstract}

Keywords: alkali-silica reactivity, mortar bars, ASR-induced expansion, fly ash, lithium nitrate, combined use of Class F fly ash and lithium salt.

\section{Introduction}

Alkali silica reactivity (ASR) is one of the major causes of the deterioration in concrete of highway structures, pavements, dam, bridges and airport. ASR is a chemical reaction that occurs between the hydroxyl ions of the alkalis, contributed primarily by Portland cement, and reactive silica in aggregates which form an alkali-silica gel. In the presence of sufficient moisture, the gel expands and produces stresses resulting in concrete cracks, spalling and other deterioration mechanisms (Stanton 1940). The ASR-induced damages can be prevented through the selection of innocuous aggregates that are not susceptible to ASR reaction. Utilizing the appropriate mitigation techniques in suppressing ASR, however, the reactive aggregates can also be safely used in the concrete (McCoy and Caldwell 1951; Touma et al. 2001; Freitag et al. 2003). The most practical and beneficial mean of suppressing ASR-induced expansion is the use of Class F fly ash as a partial replacement of Portland cement because of its economical, technical and ecological benefits (Shehata and Thomas 2000). Furthermore, fly-ash not only reduces

\footnotetext{
${ }^{1)}$ Department of Civil and Environmental Engineering and Construction Management, University of Nevada, Las Vegas, NV, USA.

${ }^{2)}$ Department of Civil Engineering, McMaster University, Hamilton, ON L8S 4L8, Canada.

*Corresponding Author; E-mail: mohammis@mcmaster.ca Copyright ( $\odot$ The Author(s) 2014. This article is published with open access at Springerlink.com
}

the amount of non-durable calcium hydroxide (lime) in concrete, but in the process it converts lime into calciumsilicate-hydrate (CSH) over time (Brough et al. 1996). Fly ash is proven to be somewhat variable in its effectiveness, principally because its composition depends on the coal properties from which it is derived (Hudec and Banahene 1993; Stark et al. 1993; Shehata and Thomas 2000; Malvar and Lenke 2006).

Lithium salts have been used as additives in concrete in order to inhibit the damages due to alkali-silica reactivity (Touma et al. 2001; Millard and Kurtis 2008; Islam 2010). McCoy and Caldwell (1951) were the first researchers to identify lithium compounds as effective admixtures in controlling ASR. The amount of lithium needed to mitigate ASR in fresh concrete is a function of sodium oxide equivalent $\left(\mathrm{Na}_{2} \mathrm{O}_{\text {eq }}\right)$ of Portland cement and the amount of cement used in concrete. The standard lithium dose, referred as $100 \% \mathrm{Li}$ dose, is the amount of $\mathrm{Li}$ admixture that supplies enough $\mathrm{Li}$ ion in the concrete to achieve a lithium-to-alkali molar ratio of 0.74 . The efficacy of lithium in suppressing expansion due to ASR strongly depends on the nature or reactivity of the aggregate, the form of lithium, and the amount of alkalis present in the concrete. The lithium nitrate rate to suppress ASR expansion of most aggregates is closed to the standard dosages of 0.74 (McCoy and Caldwell 1951; Durand 2000; Folliard et al. 2006; Ekolu et al. 2007), although highly reactive aggregates may require more, and some less reactive aggregates may need less (Touma et al. 2001; Collins et al. 2004; Islam 2010). An extensive span of lithium-to-alkali molar ratio is found effective in the previous research 
investigations; such as $0.60-0.90$ (Collins et al. 2004); 0.72-0.92 (Feng et al. 2005); 0.925 (Lane 2002); 0.74-0.93 (McKeen et al. 1998), and 0.74-1.04 (Tremblay et al. 2007).

When a large amount of Class F fly ash or lithium salt is unable to suppress ASR-induced expansion of severe reactive aggregate completely, the combination of lithium and moderate amounts of fly ash is an option to control alkalisilica reactivity efficiently (Mckeen et al. 1998; Malvar et al. 2001; Folliard et al. 2003; Johnston et al. 2002; Islam 2010). This technique requires less amount of lithium thereby reduces cost, and a smaller amount fly ash, reduces the risk on the early strength development and produces a low permeable concrete. A number of research investigations confirmed the positive effect of combining lithium compounds and fly ash in attaining the identical concrete properties without sacrificing the damages due to alkali-silica reactivity (Stark et al. 1993; McKeen et al. 1998; Johnston et al. 2002; Ramyar et al. 2004; Taha and Nounu 2008).

Previous research studies have demonstrated a substantial work to investigate the role of individual admixture, either Class F fly ash or lithium salt, in controlling alkali-silica reactivity, whereas a limited number of studies was conducted for mitigating ASR-induced expansion with the combined use of Class F fly ash and lithium salt. However, the previous studies were mostly confined to the test duration of 14 days, and aggregate types that produced a narrow range of ASR-induced expansions. Additionally, the existing investigations were unable to predict empirical equations to evaluate the optimum dosages of admixture that was sufficient enough to hold back the excessive ASR-induced expansion caused by alkali-silica reactivity.

\section{Research Significance}

The purpose of this study is to enhance the previous research investigations in comparing three mitigation techniques (the individual and combined effect of Class F fly ash and lithium salt) in inhibiting alkali-silica reactivity of four reactive aggregate groups with a large variation in ASRinduced expansion at the immersion ages of 14, 28 and 56 days. The study proposed the models in determining the optimum dosages of Class F fly and lithium nitrate salt in suppressing the excessive expansion below the prescribed limits at the above mentioned three testing periods. Additionally, the study developed a statistical analysis in selecting the combined fly ash and lithium dosage to suppress alkalisilica reactivity from the expansion reading of the mortar bars containing fly ash or lithium salt alone at their respective immersion ages.

\section{Experimental Program}

The raw materials utilized in this study consisted of four reactive aggregates, ASTM Type V Portland cement, Class F fly ash, and lithium nitrate salt. Table 1 shows the identification, chemical composition, and rock type of the selected aggregate groups. Based on the summary of findings on major rock types (mineralogy) susceptible to alkali-silica reaction in the studies conducted by Bèrubé and Fournier (1993), Islam (2010) and Islam and Akhtar (2013), andesite (RA-A and RA-C), dacite (RA-B) and basaltic-andesite (RA-D) were shown to be reactive and the results are presented in Table 1. The physico-chemical properties of Type V Portland cement, Class F fly ash and lithium nitrate salt are shown in Tables 2, 3 and 4, respectively.

The aggregate gradation, as per the requirements of ASTM C 1260, utilized to cast the test mortar bars is shown in Table 5. Water-to-SCMs ratio (by weight) of 0.47 and the graded aggregates to total cementitious materials ratio of 2.15 were used. The absorption and moisture content of the graded aggregates were included in determination of the design water-to-SCMs ratio. A constant 7-bar batch size mixture having the graded crushed aggregates of $2,310 \mathrm{~g}$ and Portland cement of $1,026.7 \mathrm{~g}$ was used to fabricate four control mortar bars of each trial aggregate source. In order to suppress excessive ASR-induced expansion of control mortar bars, each aggregate group was treated with Class $\mathrm{F}$ fly ash dosages of $15,20,25$ and $30 \%$ by weight as a partial replacement of Portland cement, up to six dosages of lithium-to-alkali molar ratios of $0.59,0.74,0.89,1.04,1.19$, and 1.33 , and the combined use of lithium-to-alkali molar ratio of 0.74 and the fly ash dosages of 15 and $20 \%$ as a partial replacement of Portland cement. It was noted that the ASTM C 1260 test was modified by adding lithium into the soak solution to maintain the same lithium-to-alkali molar ratio in the mortar bars and the soak solution (Berra et al. 2003; Folliard et al. 2003; Collins et al. 2004; Li 2005). Table 6 documents the lithium-to-alkali molar ratio and amount of lithium nitrate in the mortar bars and $1 \mathrm{~L}$ of $\mathrm{NaOH}$ solution. Amount of Portland cement, fly ash and lithium salt in the

Table 1 The identification, chemical composition, rock type and potential ASR reactivity of the selected aggregates.

\begin{tabular}{|c|c|c|c|c|c|c|c|c|c|c|}
\hline \multirow[t]{2}{*}{ Agg. ID } & \multicolumn{8}{|c|}{ Chemical composition (\%) } & \multirow[t]{2}{*}{ Rock type } & \multirow{2}{*}{$\begin{array}{c}\text { Potential } \\
\text { ASR } \\
\text { reactivity }\end{array}$} \\
\hline & $\mathrm{SiO}_{2}$ & $\mathrm{Al}_{2} \mathrm{O}_{3}$ & $\mathrm{Fe}_{2} \mathrm{O}_{3}$ & $\mathrm{CaO}$ & $\mathrm{MgO}$ & $\mathrm{Na}_{2} \mathrm{O}$ & $\mathrm{K}_{2} \mathrm{O}$ & LOI & & \\
\hline RA-A & 60.82 & 15.89 & 5.37 & 4.34 & 2.49 & 3.57 & 3.73 & 2.14 & Andesite & Reactive \\
\hline RA-B & 68.00 & 15.48 & 2.86 & 1.14 & 0.94 & 4.52 & 5.40 & 0.63 & Dacite & Reactive \\
\hline $\mathrm{RA}-\mathrm{C}$ & 59.33 & 17.15 & 5.83 & 5.30 & 2.54 & 3.76 & 2.68 & 1.83 & Andesite & Reactive \\
\hline RA-D & 52.50 & 18.45 & 8.35 & 8.36 & 4.59 & 3.74 & 1.22 & 0.98 & $\begin{array}{c}\text { Basaltic- } \\
\text { andesite }\end{array}$ & Reactive \\
\hline
\end{tabular}


Table 2 Physico-chemical properties of Type V Portland cement.

\begin{tabular}{|c|c|c|c|}
\hline \multicolumn{2}{|c|}{ Chemical composition } & \multirow{2}{*}{\multicolumn{2}{|c|}{ Physical properties }} \\
\hline Element & Percent & & \\
\hline \multicolumn{2}{|c|}{ Metal oxide } & \multicolumn{2}{|c|}{ Specific surface } \\
\hline $\mathrm{SiO}_{2}$ & 21.0 & Blaine fineness $\left(\mathrm{cm}^{2} / \mathrm{g}\right)$ & 3,760 \\
\hline $\mathrm{Al}_{2} \mathrm{O}_{3}$ & 3.6 & \multicolumn{2}{|c|}{ Soundness } \\
\hline $\mathrm{Fe}_{2} \mathrm{O}_{3}$ & 3.4 & Autoclave expansion (\%) & 0.11 \\
\hline $\mathrm{CaO}$ & 63.1 & Air content $(\%)$ & 6.7 \\
\hline $\mathrm{MgO}$ & 4.7 & Normal consistency (\%) & 24.5 \\
\hline $\mathrm{SO}_{3}$ & 2.6 & \multicolumn{2}{|c|}{ Time of setting (min) } \\
\hline \multicolumn{2}{|c|}{ Alkali oxide } & Initial set & 109 \\
\hline $\mathrm{Na}_{2} \mathrm{O}_{\text {equv }}$ & 0.42 & Final set & 212 \\
\hline \multicolumn{2}{|c|}{ Phase analysis } & \multicolumn{2}{|c|}{ Min. compressive strength } \\
\hline $\mathrm{C}_{3} \mathrm{~S}$ & 61 & \multicolumn{2}{|c|}{1,160 psi (3 days) } \\
\hline $\mathrm{C}_{2} \mathrm{~S}$ & 15 & \multicolumn{2}{|c|}{ 2,180 psi (7 days) } \\
\hline $\mathrm{C}_{3} \mathrm{~A}$ & 4 & & \\
\hline $\mathrm{C}_{4} \mathrm{AF}$ & 10 & & \\
\hline Loss on ignition & 1.3 & & \\
\hline Insoluble residue & 0.28 & & \\
\hline
\end{tabular}

Table 3 Physico-chemical properties of Class F fly ash.

\begin{tabular}{|c|c|c|c|}
\hline \multicolumn{2}{|c|}{ Chemical composition } & \multirow{2}{*}{\multicolumn{2}{|c|}{ Physical properties }} \\
\hline Element & Percent & & \\
\hline \multicolumn{2}{|c|}{ Metal oxide } & Specific gravity & 2.26 \\
\hline $\mathrm{SiO}_{2}$ & 57.8 & Retained on \#325 & $19 \%$ \\
\hline $\mathrm{Al}_{2} \mathrm{O}_{3}$ & 21.7 & Water requirement & $93 \%$ \\
\hline $\mathrm{Fe}_{2} \mathrm{O}_{3}$ & 5.1 & Autoclave expansion & 0.01 \\
\hline $\mathrm{CaO}$ & 7.4 & & \\
\hline $\mathrm{SO}_{3}$ & 0.5 & & \\
\hline Total alkali $\left(\mathrm{Na}_{2} \mathrm{O}_{\mathrm{eq}}\right)$ & 0.3 & & \\
\hline Loss on ignition & 0.2 & & \\
\hline Moisture content & 0.0 & & \\
\hline
\end{tabular}

mortar bars containing both Class F fly ash and lithium salt is shown in Table 7.

The mortar bars were mixed in accordance with the requirements of ASTM C 305, and molded within a total mixing time of not more than $2.25 \mathrm{~min}$. After $24 \mathrm{~h}$ of moist curing, the bars were demolded, and initial readings were taken before immersing in water at $80{ }^{\circ} \mathrm{C}$ for $24 \mathrm{~h}$ for which the zero readings were recorded. Afterward, the mortar bars were submerged in a $\mathrm{NaOH}$ solution of $1 \mathrm{~N}$ concentration in an air-tight plastic container held in an oven maintaining the temperature of $80{ }^{\circ} \mathrm{C}$. Subsequent readings were taken at the immersion ages of 3, 6, 10, 14 days and thereafter one reading per week until the immersion age of 98 days was reached.

\section{Results and Discussions}

\subsection{ASR Evaluation of the Selected Aggregates}

The ASR classification of the investigated aggregates was evaluated based on the expansion limits of mortar bars of $0.10 \%$ at 14 days, suggested by ASTM C 1260, and $0.28 \%$ at 28 days, and $0.47 \%$ at 56 days, proposed by by Islam (2010) and Islam and Ghafoori (2013). Additionally, the 
Table 4 Physico-chemical properties of lithium nitrate salt.

\begin{tabular}{|c|c|}
\hline \multicolumn{2}{|c|}{ Physical properties } \\
\hline Appearance & Clear, water white to yellow solution \\
\hline Odor & Odorless \\
\hline Solubility in water & Soluble in any proportion \\
\hline Oxidizing characteristic & Oxidizer \\
\hline \multicolumn{2}{|c|}{ Chemical properties } \\
\hline $\mathrm{pH}$ & $7-9.5$ at $25^{\circ} \mathrm{C}$ \\
\hline Boiling point & $110-120^{\circ} \mathrm{C}$ \\
\hline Specific gravity & $1.2-1.3 \mathrm{~g} / \mathrm{cc}$ at $25^{\circ} \mathrm{C}$ \\
\hline Molecular weight & 68.95 \\
\hline \multicolumn{2}{|c|}{ Chemical compositions } \\
\hline Lithium nitrate & $30 \%$ \\
\hline Water & $70 \%$ \\
\hline
\end{tabular}

Table 5 Crushed aggregate gradation for mortar bar specimens.

\begin{tabular}{c|c|c}
\hline \multicolumn{2}{c|}{ Sieve size } & Mass \\
\hline \hline Passing & Retained on & 10 \\
\hline $2.75 \mathrm{~mm}($ no. 4) & $2.36 \mathrm{~mm}$ (no. 8) & 25 \\
\hline $1.18 \mathrm{~mm}$ (no. 16) & $1.18 \mathrm{~mm}$ (no. 16) & 25 \\
\hline $600 \mu \mathrm{m}($ no. 30) & $600 \mu \mathrm{m}$ (no. 30) & 25 \\
\hline $300 \mu \mathrm{m}($ no. 50) & $300 \mu \mathrm{m}$ (no. 50) & 15 \\
\hline
\end{tabular}

Table 6 Lithium-to-alkali molar ratio and amount of lithium nitrate in the mortar bars and $1 \mathrm{~L}$ of $\mathrm{NaOH}$ solution.

\begin{tabular}{|c|c|c|c|c|c|}
\hline \multirow{2}{*}{$\frac{\mathrm{Li}}{\mathrm{Na}+\mathrm{K}}$} & \multirow[t]{2}{*}{$\mathrm{LiNO}_{3}^{\mathrm{a}}$ in mortars $(\mathrm{g})$} & \multicolumn{4}{|c|}{$1.0 \mathrm{~L}$ of $1 \mathrm{~N} \mathrm{NaOH}$ solution } \\
\hline & & $\frac{\mathrm{Li}}{\mathrm{Na}+\mathrm{K}}$ & Water $^{\mathrm{b}}(\mathrm{g})$ & $\mathrm{LiNO}_{3}(\mathrm{~g})$ & $\mathrm{NaOH}(\mathrm{g})$ \\
\hline 0.59 & 37.78 & 0.295 & 952.50 & 67.93 & 40 \\
\hline 0.74 & 47.23 & 0.370 & 940.56 & 84.92 & \\
\hline 0.89 & 56.67 & 0.445 & 928.70 & 101.90 & \\
\hline 1.04 & 66.12 & 0.520 & 916.80 & 118.90 & \\
\hline 1.18 & 75.56 & 0.590 & 904.90 & 135.86 & \\
\hline 1.33 & 85.01 & 0.665 & 893.00 & 152.90 & \\
\hline
\end{tabular}

${ }^{a}$ Based on 7-bar size mixture.

${ }^{\mathrm{b}}$ Distilled water was added to prepare $\mathrm{NaOH}$ solution.

Table 7 Amount of Portland cement, fly ash and lithium salt in the mortar bars containing both Class F fly ash and lithium salt.

\begin{tabular}{c|c|c|c}
\hline Design Criteria & Portland cement $(\mathrm{g})$ & Fly ash $(\mathrm{g})$ & Lithium $(\mathrm{g})$ \\
\hline \hline $15 \% \mathrm{FA}+100 \% \mathrm{Li}$ & 872.7 & 154.0 & 47.23 \\
\hline $20 \% \mathrm{FA}+100 \% \mathrm{Li}$ & 821.3 & 205.4 & 47.23 \\
\hline
\end{tabular}

\footnotetext{
${ }^{a}$ Based on 7-bar size mixture.
} 
(a)

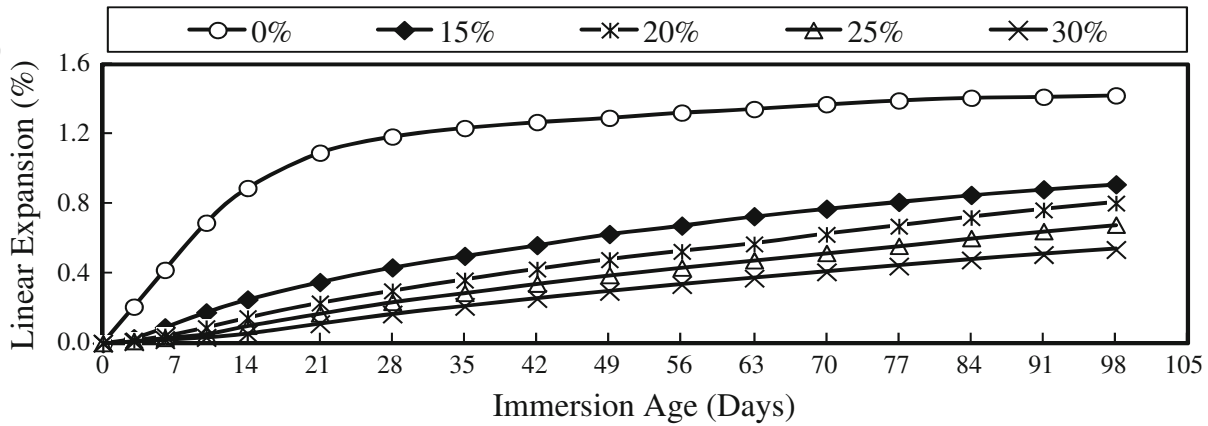

(b)

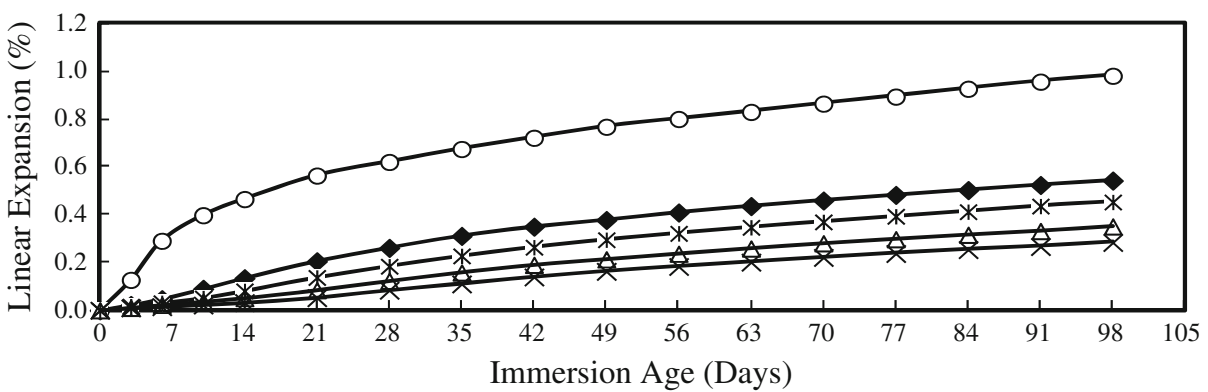

(c)

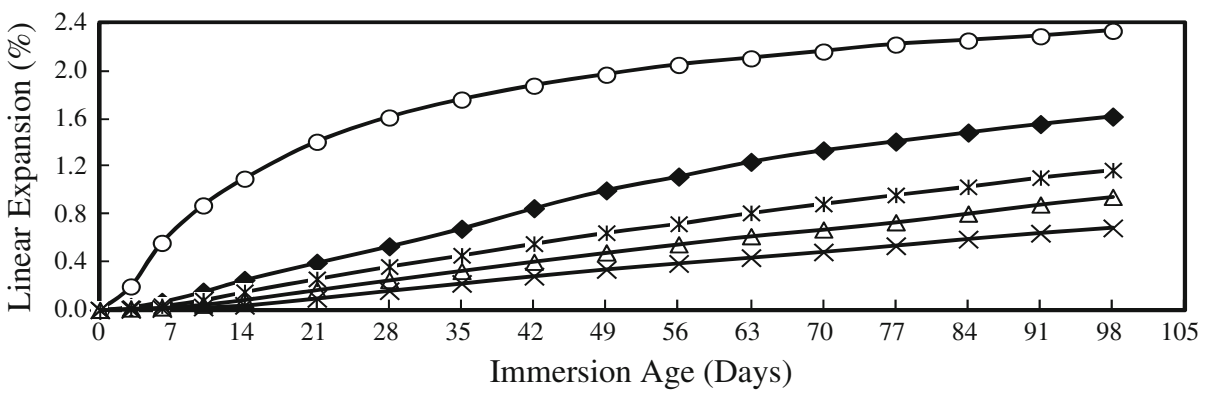

(d)

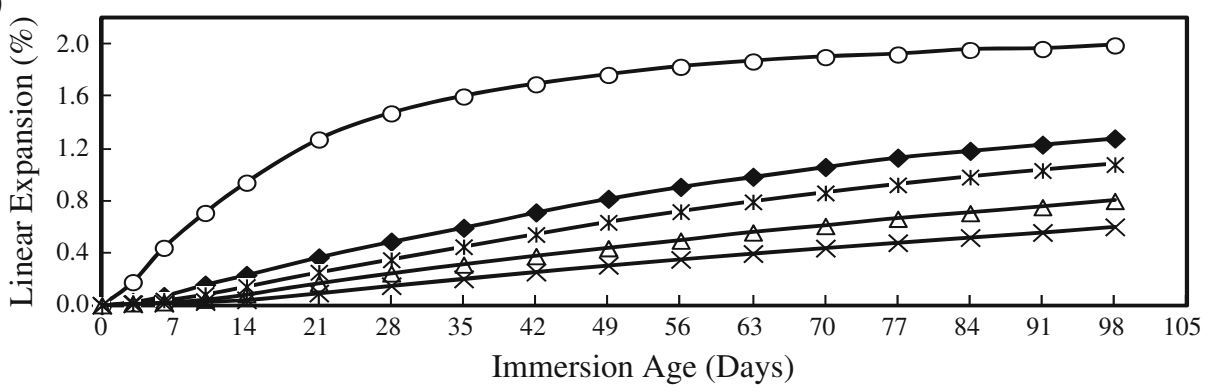

Fig. 1 Expansion progression of mortar bars made with various dosages of Class $F$ fly ash and a RA-A, b RA-B, $\mathbf{c}$ RA-C, and d RA-D aggregates.

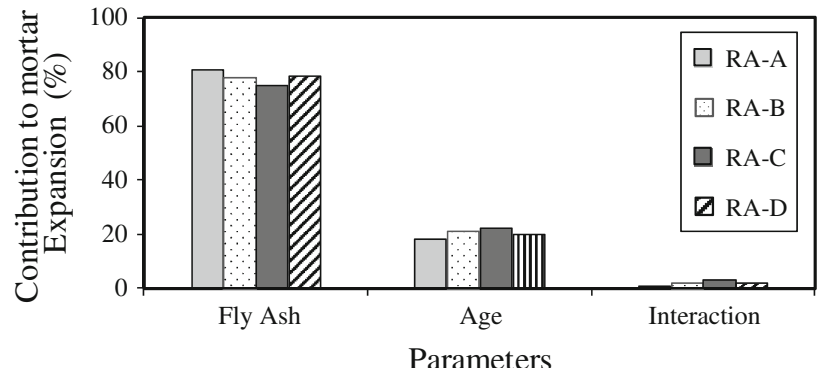

Fig. 2 Percent contribution to mortar expansion due to Class $F$ fly ash, immersion age and their interaction.

extended failure criteria of $0.33 \%$ at 28 days and $0.48 \%$ at 56 days, proposed by Hooton (1995), and Hooton and Rogers (1993), were also applied to assess the aggregate's susceptibility due to alkali-silica reactivity. All aggregates tested in this study were considered as reactive based on the above mentioned 14-, 28- and 56-day failure criteria. The mineralogy of aggregates also produced the similar ASR classification with that obtained by the expansion limits at the three test durations. Since the alkali-silica reaction is a complex meachanism that depends on a number of factors, it was highly recommended to use the conservative expansion limits in evaluating the reactivity of an aggregate. As such, in this study, the 28- and 56-day extended failure criteria of 0.28 and $0.47 \%$, respectively, were utilized.

\subsection{Controlling ASR-Induced Expansion Using Class F Fly Ash}

Figure 1 shows that expansion progression of mortar bars made with various dosages of Class $\mathrm{F}$ fly ash and each 
aggregate group. The ASR-induced expansion of each aggregate group as related to Class F fly ash and immersion age is shown in Fig. 1. As can be seen, the expansion of the test mortar bars increased with an increase in test duration,

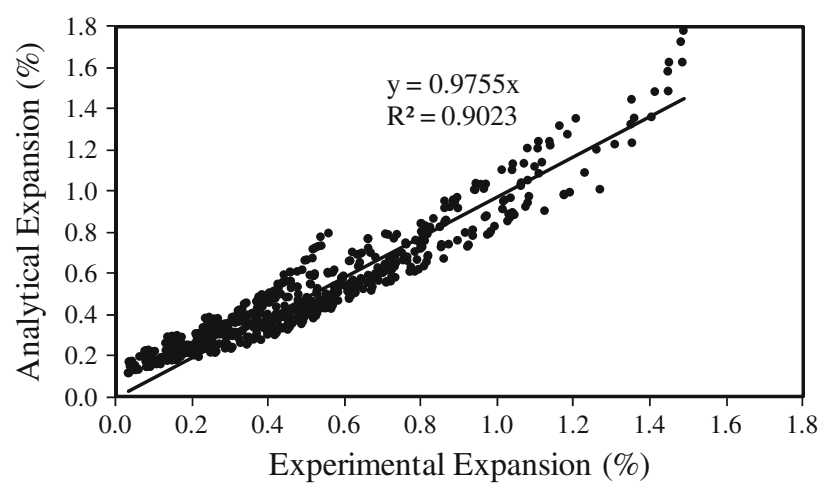

Fig. 3 Comparison of experimental and analytical ASRinduced expansion. and decreased with increasing fly ash content. The rate of expansion was extensive at the early immersion age for the control specimens, and it reduced with replacing Portland cement by weight with Class F fly ash. The results revealed the optimistic influence of the selected dosages of Class F fly ash in reducing the adverse effect of reactive aggregates.

\subsubsection{Percent Contribution to Mortar Expansion due to Class F Fly Ash, Immersion Age and Their Interaction}

The experimental mortar expansion of each aggregate group consisted of two factors of Class $\mathrm{F}$ fly ash and immersion age with three levels at each setting: three immersion ages of 14, 28 and 56 days, and three rates of Class F fly ash of 0,15 and $30 \%$. A full factorial analysis was performed to evaluate the effect of each factor (fly ash and immersion age) and their interaction on the response variable (which was ASR-induced expansion). The results are provided in Fig. 2. The plot demonstrates that, for all

Table 8 Optimum experimental and analytical Class F fly ash dosage at various immersion ages.

\begin{tabular}{|c|c|c|c|c|c|}
\hline Aggregate ID & $\begin{array}{l}\text { Immersion age } \\
\text { (days) }\end{array}$ & $\begin{array}{c}\text { Control expansion } \\
(\%)\end{array}$ & $\begin{array}{c}\text { Expansion of treated } \\
\text { bars below failure } \\
\text { limit }(\%)\end{array}$ & $\begin{array}{c}\text { Experimental Class } \mathrm{F} \\
\text { fly ash }(\%)\end{array}$ & $\begin{array}{c}\text { Analytical Class F fly } \\
\text { ash dosage }(\%)\end{array}$ \\
\hline \multirow[t]{3}{*}{ RA-A } & 14 & 0.890 & 0.099 & 25 & 37.9 \\
\hline & 28 & 1.185 & 0.236 & 25 & 27.6 \\
\hline & 56 & 1.323 & 0.434 & 25 & 22.7 \\
\hline \multirow[t]{3}{*}{ RA-B } & 14 & 0.465 & 0.081 & 20 & 36.8 \\
\hline & 28 & 0.620 & 0.261 & 15 & 19.3 \\
\hline & 56 & 0.800 & 0.409 & 15 & 17.9 \\
\hline \multirow[t]{3}{*}{ RA-C } & 14 & 1.098 & 0.081 & 25 & 44.0 \\
\hline & 28 & 1.610 & 0.251 & 25 & 31.3 \\
\hline & 56 & 2.050 & 0.389 & 30 & 33.0 \\
\hline \multirow[t]{3}{*}{ RA-D } & 14 & 0.940 & 0.084 & 25 & 41.5 \\
\hline & 28 & 1.472 & 0.244 & 25 & 30.2 \\
\hline & 56 & 1.828 & 0.352 & 30 & 32.3 \\
\hline
\end{tabular}

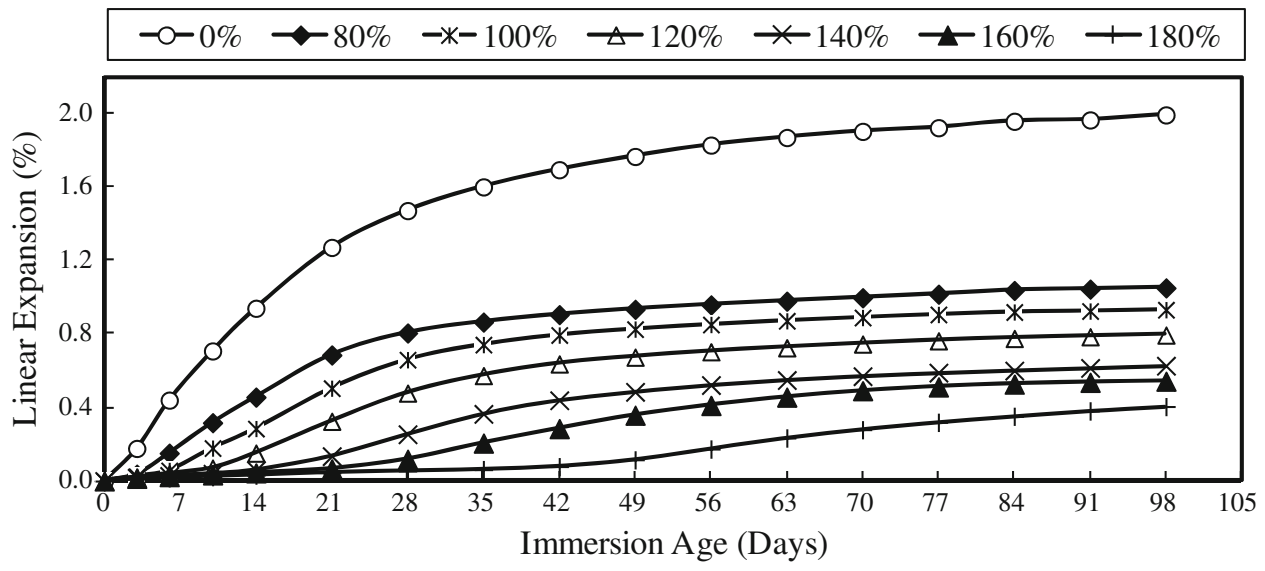

Fig. 4 ASR-induced expansion of the mortar bars made with RA-D aggregate and various lithium dosages. 


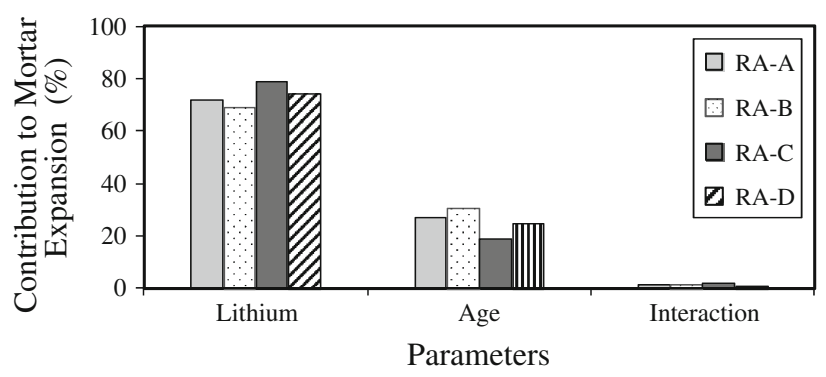

Fig. 5 Percent contribution to mortar expansion due to lithium salt, immersion age, and their interaction.

trial aggregates, the percent contribution to ASR-induced expansion (PCE) due to immersion age, Class F fly ash, and the combined influence of immersion age and fly ash was shown to be nearly consistent (approximately $20 \%$ due to immersion age, $78 \%$ due to Class $\mathrm{F}$ fly ash, and $2 \%$ due their combined effect). The results demonstrated that aggregate mineralogy had less influence on the percent contribution to ASR-induced expansion of mortar bars treated with when Class F fly ash.

\subsubsection{Empirical Modelling to Predict the Optimum} Analytical Class F Fly Ash Dosage

ASR-induced expansion of fly-ash containing mortar bars $\left(\operatorname{Exp}_{F A}\right)$ as related to control expansion $\left(\operatorname{Exp}_{C E}\right)$, immersion age $(t)$ and Class $\mathrm{F}$ fly ash dosage $(F)$ was evaluated, and the results were expressed in Eq. (1). A very good correlation, with an $\mathrm{R}^{2}$ value of 0.90 , existed between the experiment and predicted expansion of fly-ash mortar bars as shown in Fig. 3. The The model was appropriate for a wide range of Class F fly ash (0-30), ASR-induced expansion, and immersion age (14-98 days). For the proposed model, the absolute $t$-ratio and $\operatorname{Prob}(t)$ for all regression coefficients were found to be highly significant. Additionally, the F-ratio of the model was found to be very high that shows the model parameter's significance. Finally, percent Class F fly ash dosage can be expressed in Eq. (2) by taking natural logarithm in both sides of Eq. (1).

The optimum analytical Class F fly ash dosage required to hold the control expansion below the prescribed failure limits of mortar bars at the ages of 14, 28 and 56 days was evaluated. The results are shown in Table 8 . As can be seen, there is a good agreement between the optimum experimental fly ash content and the analytical fly ash dosage at the ages of 28 and 56 days. However, the results obtained at the early age of 14 days were inconsistent and were to be more conservatives. The main reasons can be stated as follows:

- ASR-induced expansion of fly-ash containing mortar bars made with trial aggregate groups at early age ( $<14$ days) varied abruptly,

- ASR-induced expansion below 14 days was not critical in evaluating alkali-silica reactivity, and

- expansion rate below the early immersion age differed over a wide range, and did not follow any distinct pattern.

$$
\begin{aligned}
& \operatorname{Exp}_{F A}= \exp \left(-0.940+0.613 \operatorname{Exp}_{C E}+0.00928 t\right. \\
&-0.0540 F) \\
& F=\frac{1}{0.054}\left[-0.940+0.613 \operatorname{Exp}_{C E}+0.00928 t-\ln \left(\operatorname{Exp}_{F A}\right)\right]
\end{aligned}
$$

where $\operatorname{Exp}_{F A}$ and $\operatorname{Exp}_{C E}$ are the percent linear expansions of fly ash treated mortar bars and control mortar bars, respec-

\begin{tabular}{|c|c|c|c|c|c|}
\hline Aggregate ID & $\begin{array}{l}\text { Immersion age } \\
\text { (days) }\end{array}$ & $\begin{array}{c}\text { Control expansion } \\
(\%)\end{array}$ & $\begin{array}{l}\text { Expansion of treated } \\
\text { bars below failure } \\
\text { limit }^{\mathrm{a}}(\%)\end{array}$ & $\begin{array}{c}\text { Experimental lithium } \\
\text { dosage }\end{array}$ & $\begin{array}{c}\text { Analytical lithium } \\
\text { dosage }\end{array}$ \\
\hline \multirow[t]{3}{*}{ RA-A } & 14 & 0.890 & 0.074 & 0.89 & 1.03 \\
\hline & 28 & 1.185 & 0.248 & 0.89 & 0.98 \\
\hline & 56 & 1.323 & 0.464 & 1.04 & 0.92 \\
\hline \multirow[t]{3}{*}{ RA-B } & 14 & 0.465 & 0.075 & 0.74 & 0.90 \\
\hline & 28 & 0.620 & 0.216 & 0.59 & 0.85 \\
\hline & 56 & 0.800 & 0.447 & 0.59 & 0.78 \\
\hline \multirow[t]{3}{*}{ RA-C } & 14 & 1.098 & 0.073 & 0.89 & 1.10 \\
\hline & 28 & 1.610 & 0.265 & 0.89 & 1.09 \\
\hline & 56 & 2.050 & 0.453 & 1.04 & 1.17 \\
\hline \multirow[t]{3}{*}{ RA-D } & 14 & 0.940 & 0.059 & 1.04 & 1.07 \\
\hline & 28 & 1.472 & 0.254 & 1.04 & 1.07 \\
\hline & 56 & 1.828 & 0.411 & 1.19 & 1.16 \\
\hline
\end{tabular}
tively; $t$ is immersion age in days, $F$ is Class $\mathrm{F}$ fly ash

Table 9 Optimum experimental and analytical lithium dosage of each aggregate group at various immersion ages.

${ }^{a}$ Less than $0.10 \%$ at 14 days, $0.28 \%$ at 28 days, and $0.47 \%$ at 56 days. 


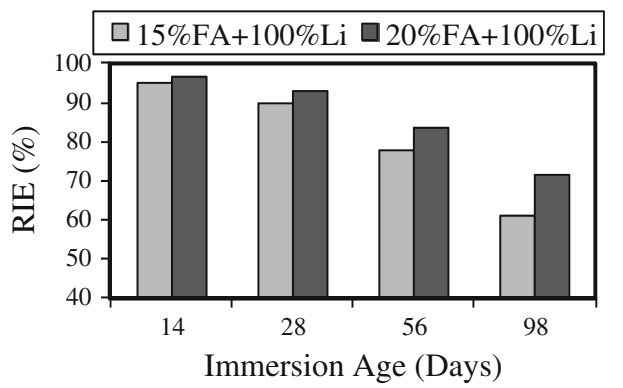

(a)

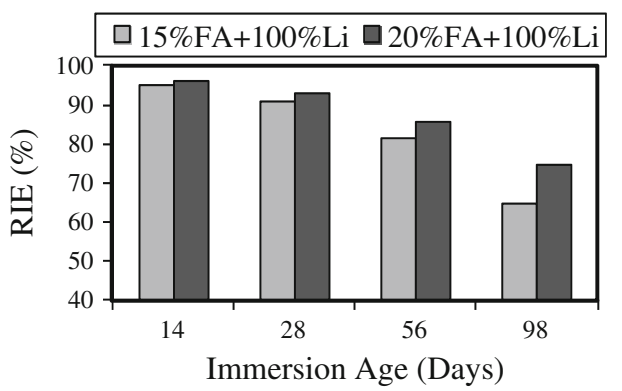

(a)

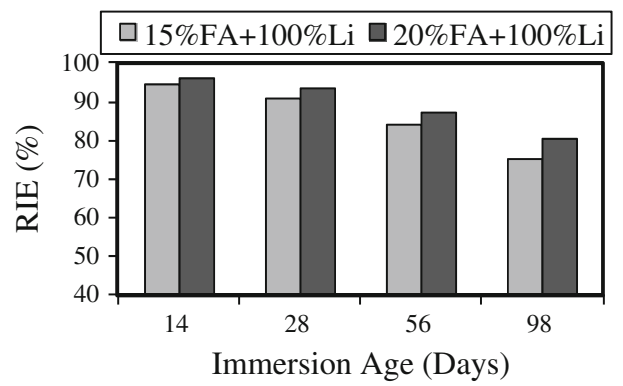

(b)

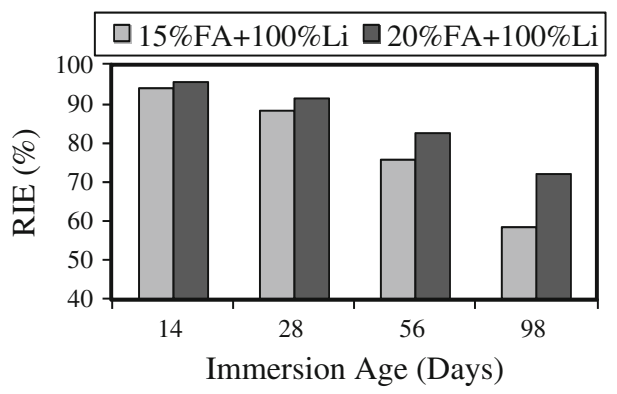

(b)

Fig. 6 RIE of mortar bars prepared with two dosages of Class F fly (15 and $20 \%$ ) and lithium-to-alkali molar ratio of 0.74 (100 \% $\mathrm{Li}$ ) at various immersion ages. a RA-A aggregate. b RA-B aggregate. c RA-C aggregate. d RA-D aggregate.

dosages (in percent) as a partial replacement of Portland cement by weight.

\subsection{Controlling ASR-Induced Expansion Using Lithium Salt}

The results of the study clearly revealed that the selected lithium nitrate dosages reduced the adverse effect of alkalisilica reactivity for the four reactive aggregates. A typical ASR expansion as a function of the immersion age and lithium-to-alkali molar ratio is shown in Fig. 4. As can be seen, the expansion of control mortar bars expanded rapidly at the early age of immersion, and the expansion rate decreased with an increase in the immersion age. In the case of lithium-bearing mortar bars, the expansion rate was fairly small throughout the test duration. Additionally, the mortar bars containing lithium salt showed little tendency to expand after the immersion age of 2 months. The results of the study clearly revealed that the selected lithium nitrate dosages reduced the harmful effect of alkali-silica reactivity for the selected reactive aggregate groups. The expansion rate of lithium-bearing mortar bars was fairly small throughout the test duration. Additionally, those specimens showed little tendency to expand after the immersion age of 2 months. The expansion behavior of the remaining three aggregates groups over the immersion age also followed the similar pattern to that of the AR-D aggregate.

\subsubsection{Percent Contribution to Mortar Expansion} due to Lithium Salt, Immersion Age and Their Interaction

A full-factorial analysis was conducted to evaluate the percent contribution to ASR-induced expansion (PCE) due to lithium salt, immersion age, and their interaction. The results are presented in Fig. 5. The plot demonstrates that percent contribution to ASR-induced expansion for all trial aggregates due to immersion age varied from 18.86 to $30.06 \%$ with an average of $25.5 \%$, and that of lithium salt differed from 68.70 to $78.32 \%$ with an average of $73.32 \%$, respectively, and the interaction of immersion age and lithium salt contributed about $1.3 \%$ to ASR-induced expansion. The PCE due to immersion age and lithium salt for the investigated aggregate groups was more diverged as compared to that obtained due to immersion age and fly ash (Fig. 2). As such, suppressing alkali-silica reactivity using the lithium salt depended mainly on aggregate mineralogy.

\subsubsection{Empirical Modeling to Predict the Optimum Analytical Lithium Dosage}

Equation (3) represents the ASR-induced expansion of lithium-containing mortar bars, which is mainly depended on three independent variables (factors) such as control expansion, lithium salt, and immersion age. The model was appropriate for a wide range of lithium-to-alkali molar ratio (0-1.19), ASRinduced expansion, and immersion age (14-98 days). For the proposed model, the statistical analysis for all regression coefficients were tested and found to be highly significant. Additionally, the F-ratio of the model was found to be very high that shows the model parameter's significance. The empirical model to evaluate the optimum lithium content for all trial aggregate groups is expressed in Eq. (4), which is derived from Eq. (3).

$$
\begin{aligned}
& \operatorname{Exp}_{L i}=0.5535+0.2285 \operatorname{Exp}_{C E}+0.00504 t-0.712 L i \\
& L i=\frac{1}{0.712\left(0.5535+0.2285 \operatorname{Exp}_{C E}+0.00504 t-\operatorname{Exp}_{L i}\right)}
\end{aligned}
$$


where $\operatorname{Exp}_{C E}$ and $\operatorname{Exp}_{L i}$ are the percent linear expansion of untreated mortar bars and that of treated specimens, respectively; $t$ is immersion age in days, $L i$ is lithium-toalkali molar ratio.

The proposed empirical model predicted the optimum lithium dosage of each reactive aggregate that was sufficient enough to suppress the control expansion $\left(\operatorname{Exp}_{\text {con }}\right)$ below the prescribed failure limits at the immersion ages of 14, 28 and 56 days. The results are shown in Table 9. The proposed empirical model generated the minimum lithium content for each trial aggregate at three immersion ages was in a good agreement with the result obtained by the experimental procedures.

\subsection{Controlling ASR-Induced Expansion Using the Combination of Class F Fly Ash and Lithium Salt}

The effectiveness of the combined use of Class F fly ash and lithium salt was also expressed in terms of the Reduction in Expansion (RIE) of the untreated mortar bars (having no fly ash or lithium content). Figure 6 shows the RIE of mortar bars prepared with two dosages of Class F fly (15 and $20 \%$ ) and lithium-to-alkali molar ratio of $0.74(100 \% \mathrm{Li})$ at various immersion ages. As can be shown, the 14-day RIE of the treated mortar bars made with the selected aggregates varied from 93.9 to $95.2 \%$ with an average of $94.7 \%$ for $15 \% \mathrm{FA}+100 \% \mathrm{Li}$, and $95.6-96.7 \%$ with an average of $96.1 \%$ for $20 \% \mathrm{FA}+100 \% \mathrm{Li}$. The RIE decreased with an increase in test duration. At the extended immersion age of 98 days, the expansion values differed from 58.50 to $75.03 \%$ with an average of $64.88 \%$ for the $15 \%$
$\mathrm{FA}+100 \% \mathrm{Li}$, and $71.69-80.22 \%$ with an average of $74.73 \%$ for the $20 \% \mathrm{FA}+100 \% \mathrm{Li}$. Overall, the results illustrated that the difference in the 14-day RIE among the trial aggregates was fairly insignificant as compared to that at the immersion age of 98 days.

\subsubsection{Empirical Modeling to Predict ASR-Induced Expansion of Mortar Bars Prepared with Both Class F Fly Ash and Lithium Salt}

A correlation was observed between the expansion of mortar bars made with combined fly ash and lithium dosages with the expansion of mortar bars having the dosage of admixture, that of untreated specimen, and immersion age. Equations (5) and (6) show the empirical models in evaluating the expansion of mortars made with $15 \%$ Class F fly ash and lithium-to-alkali molar ratio of $0.74(100 \% \mathrm{Li}$ dosage), and that prepared with $20 \%$ Class F fly ash and lithium-to-alkali molar ratio of 0.74 , respectively. The $\mathrm{R}^{2}$ values of the proposed models, higher than $98 \%$, indicated a good fit between the 14-, 28-, and 56-day expansion of the mortar bars made with Class F fly ash, lithium nitrate, and that containing both fly ash and lithium.

$$
\begin{aligned}
\operatorname{Exp}_{F 15+L 0.74}= & \exp \left(-4.507+1.108 \operatorname{Exp}_{C E}+0.0172 t\right. \\
& \left.-1.470 \operatorname{Exp}_{F 15}+2.400 \operatorname{Exp}_{L i}\right) \\
\operatorname{Exp}_{F 20+L 0.74}= & \exp \left(-2.560-0.848 \operatorname{Exp}_{C E}-0.0056 t\right. \\
& \left.+2.281 \operatorname{Exp}_{F 20}+2.227 \operatorname{Exp}_{L i}\right)
\end{aligned}
$$

\begin{tabular}{|c|c|c|c|c|c|c|c|c|}
\hline \multirow[t]{2}{*}{ Agg. ID } & \multirow[t]{2}{*}{$\begin{array}{c}\text { Immersion age } \\
\text { (days) }\end{array}$} & \multicolumn{5}{|c|}{ Experimental expansion (\%) due to } & \multicolumn{2}{|c|}{$\begin{array}{l}\text { Analytical expansion (\%) due } \\
\text { to }\end{array}$} \\
\hline & & $15 \% \mathrm{FA}$ & $20 \% \mathrm{FA}$ & $100 \% \mathrm{Li}$ & $\begin{array}{c}15 \% \\
\mathrm{FA}+100 \% \\
\mathrm{Li} \\
\end{array}$ & $\begin{array}{c}20 \% \\
\text { FA }+100 \% \\
\mathrm{Li} \\
\end{array}$ & $\begin{array}{c}15 \% \\
\mathrm{FA}+100 \% \\
\mathrm{Li} \\
\end{array}$ & $\begin{array}{c}20 \% \\
\mathrm{FA}+100 \% \\
\mathrm{Li} \\
\end{array}$ \\
\hline \multirow[t]{3}{*}{ RA-A } & 14 & 0.251 & 0.146 & 0.166 & 0.042 & 0.030 & 0.039 & 0.068 \\
\hline & 28 & 0.434 & 0.300 & 0.401 & 0.118 & 0.084 & 0.092 & 0.117 \\
\hline & 56 & 0.674 & 0.526 & 0.720 & 0.292 & 0.220 & 0.262 & 0.304 \\
\hline \multirow[t]{3}{*}{ RA-B } & 14 & 0.134 & 0.081 & 0.076 & 0.025 & 0.018 & 0.023 & 0.069 \\
\hline & 28 & 0.261 & 0.184 & 0.175 & 0.055 & 0.041 & 0.037 & 0.088 \\
\hline & 56 & 0.409 & 0.322 & 0.352 & 0.128 & 0.104 & 0.098 & 0.143 \\
\hline \multirow[t]{3}{*}{$\mathrm{RA}-\mathrm{C}$} & 14 & 0.251 & 0.152 & 0.179 & 0.052 & 0.042 & 0.050 & 0.060 \\
\hline & 28 & 0.532 & 0.363 & 0.485 & 0.146 & 0.111 & 0.156 & 0.114 \\
\hline & 56 & 1.116 & 0.721 & 0.877 & 0.386 & 0.296 & 0.446 & 0.364 \\
\hline \multirow[t]{3}{*}{ RA-D } & 14 & 0.233 & 0.144 & 0.286 & 0.057 & 0.042 & 0.056 & 0.085 \\
\hline & 28 & 0.488 & 0.349 & 0.660 & 0.175 & 0.125 & 0.217 & 0.183 \\
\hline & 56 & 0.854 & 0.718 & 0.852 & 0.447 & 0.321 & 0.482 & 0.412 \\
\hline
\end{tabular}

Table 10 The optimum experimental and analytical lithium-to-alkali molar ratio for each reactive aggregate at various immersion ages.

\footnotetext{
${ }^{\text {a }}$ Less than $0.10 \%$ at 14 days, $0.28 \%$ at 28 days, and $0.47 \%$ at 56 days.
} 
Table 11 Effective mitigation techniques to suppress alkali-silica reactivity.

\begin{tabular}{c|c|c|c|c|c|c|c|c|c}
\hline \multirow{2}{*}{ Agg. ID } & \multicolumn{4}{|c|}{$\begin{array}{c}\text { 14-Day expansion limit of } 0.10 \% \\
\text { (ASTM C 1260) }\end{array}$} & \multicolumn{2}{c|}{ 28-Day expansion limit of 0.28 \% } & \multicolumn{3}{c}{56 -Day expansion limit of 0.47 \% } \\
(Islam 2010) 2010)
\end{tabular}

FA Class F fly ash, $L i$ lithium-to-alkali molar ratio.

where $\operatorname{Exp}_{F 15+L 0.74}$ and $\operatorname{Exp}_{F 20+L 0.74}$ are the percent ASRinduced expansions of specimens due to the combined effects of $15 \%$ fly ash and $100 \% \mathrm{Li}$ and those prepared with $20 \%$ Class F fly ash and $100 \% \mathrm{Li}$, respectively; $\operatorname{Exp}_{C E}$ is percent control expansion; $\operatorname{Exp}_{F 15}$ and $\operatorname{Exp}_{F 20}$ are the percent linear expansions due to 15 and $20 \%$ Class F fly ash, respectively; $\operatorname{Exp}_{L i}$ is the percent expansion due to lithium-to-alkali molar ratio of $0.74 ; t$ is immersion age in days.

The analytical ASR-induced expansion of the mortar bars containing both fly ash and lithium salt at the immersion ages of 14, 28 and 56 days was evaluated by using Eqs. (5) and (6), and the outcomes are shown in Table 10. The test results were compared with the experimental expansion of the mortar bars containing both fly ash and lithium nitrate. A linear correlation with $\mathrm{R}^{2}$ values of 0.986 and 0.982 was observed between the analytical and experimental results for the mortar bars containing $15 \% \mathrm{FA}+100 \% \mathrm{Li}$ and $20 \%$ $\mathrm{FA}+100 \% \mathrm{Li}$, respectively.

\subsection{Comparison of Various ASR Mitigation Techniques}

Table 11 documents the levels of alkali-silica reactivity of the selected aggregates based on the suggested expansion criteria of ASTM C 1260 at 14, 28 and 56 days. As can be seen, various techniques in controlling the ASR-induced expansion at three immersion ages are effective for different aggregates. The combined use of fly ash and lithium showed very effective in suppressing the excessive expansion of the trial reactive aggregates compared to the individual effect of fly ash and lithium at the immersion age of 56 days. However, the study demonstrated that a combination of lithium nitrate at the lithium-to-alkali molar ratio of 0.74 and a minimum of $15 \%$ Class F fly ash by weight of Portland cement inhibited ASR-induced expansion of all reactive aggregates based on the suggested expansion limits at the ages of 14, 28 and 56 days. The results showed an agreement on the findings recommended by McKeen et al. (1998), Johnston et al. (2002) and Ramyar et al. (2004). The study suggested that blending $20 \%$ Class F fly ash as a partial replacement of Portland cement in conjunction with a $\mathrm{Li}:(\mathrm{Na}+\mathrm{K})$ molar ratio of 0.74 would be more effective in improving ASR mitigation of the selected aggregate quarries at three different ages.

\section{Conclusions}

The following conclusions can be drawn based on the results of this study:

- Class F fly ash, lithium salt, and their combination suppressed the excessive expansion of trial aggregate groups caused by alkali-silica reactivity. It was shown that the progression in ASR-induced expansion had the highest for the control mortar bars, followed by the specimens treated with lithium salt, Class F fly ash and finally, the combination of lithium salt and Class F fly ash.

- Most cases, the required experimental Class F fly ash and lithium dosages to suppress excessive ASR-induced expansion below $0.10 \%$ at 14 days was less than that required to reduce the expansion below $0.28 \%$ at 28 days, and $0.47 \%$ at 56 days. It was recommended to use the minimum amount of Class F fly ash and lithium nitrate to arrest the ASR-related damages based on the 14-, 28- and 56-day expansion criteria.

- The results revealed that lithium nitrate was found to be more effective for some extremely reactive aggregates, but comparatively less effective for less reactive aggregates. Additionally, lithium-bearing specimens show no tendency to expand after 2-3 months of immersion.

- The reduction in mortar expansion decreased rapidly with an increase in immersion age for the mortar bars treated with the combination of fly ash and lithium salt than that those prepared with fly ash or lithium salt alone. The mitigation technique of combined use of Class F fly ash and lithium salt was shown to be more effective in inhibiting the excessive expansions of highly reactive aggregates. The combined use of standard lithium dose (lithium-to-alkali molar ratio of 0.74 ) and a moderate amount (15\%) of Class F fly ash as a partial replacement of Portland cement by weight, arrested the ASR-related damages for the investigated four reactive aggregates at three immersion ages.

- A good agreement existed between the experimental admixture dosage and analytical admixture dosage at the immersion ages of 14, 28 and 56 days. The proposed analytical method may be used in selecting both optimum fly ash and lithium that is capable of limiting the ASR expansion of reactive aggregate below the three 
suggested failure criteria for the above-mentioned immersion ages.

- The study also suggested that different aggregates may require different mitigation techniques to limit alkalisilica reactions. The final selection of an effective mitigation technique depends on its effect on early-age and late-age ASR-induced expansions, and the potential economical benefits.

\section{Acknowledgments}

The author would like to acknowledge Nevada Department of Transportation (NDOT) for providing materials and financial support throughout the study. Thanks are also extended to the Southern Nevada Aggregate Association (SNAA) that acted as a connection between the aggregate producers and researchers. Material contributions by aggregate and cement companies are also acknowledged.

\section{Open Access}

This article is distributed under the terms of the Creative Commons Attribution License which permits any use, distribution, and reproduction in any medium, provided the original author(s) and the source are credited.

\section{References}

Berra, M., Mangialardi, T., \& Paolini, A. E. (2003). Use of lithium compounds to prevent expansive alkali-silica reactivity in concrete. Advances in Cement Research, 15(4), $145-154$.

Bèrubé, M. A., \& Fournier, B. (1993). Canadian experience with testing for alkali-aggregate reactivity in concrete. Cement \& Concrete Composites, 15, 27-47.

Brough, A. R., Dobson, C. M., Richardson, I. G., \& Groves, G. W. (1996). Alkali activation of reactive silicas in cements: In situ 29Si MAS NMR studies of the kinetics of silicate polymerization. Journal of Materials Science, 31, 3365-3373.

Collins, C. L., Ideker, J. H., Willis, G. S., \& Kurtis, K. E. (2004). Examination of the effects of $\mathrm{LiOH}, \mathrm{LiCl}$, and $\mathrm{LiNO}_{3}$ on alkali-silica reaction. Cement and Concrete Research, 34, 1403-1415.

Durand, B. (2000). More results about the use of lithium salts and mineral admixtures to inhibit ASR in concrete. In Proceedings of the 11th international conference on alkaliaggregate reaction (pp. 623-632), Centre de Recherche Interuniversitaire sur le Beton, Quebec, Canada.

Ekolu, S. O., Thomas, M. D. A., \& Hooton, R. D. (2007). Dual effectiveness of lithium salt in controlling both delayed ettringite formation and ASR in concretes. Cement and Concrete Research, 37(6), 942-947.
Feng, X., Thomas, M. D. A., Bremner, T. W., Balcom, B. J., \& Folliard, K. J. (2005). Studies on lithium salts to mitigate ASR-induced expansion in new concrete: A critical review. Cement and Concrete Research, 35, 1789-1796.

Folliard, K. J., Thomas, M. D. A., Fournier, T., Kurtis, K. E., \& Ideker, J. H. (2006). Interim recommendations for the use of lithium to mitigate or prevent alkali-silica reaction (ASR). Report no. FHWA-ART-06-073. McLean, VA: Office of Infrastructure Research and Development, Federal Highway Administrator.

Folliard, K. J., Thomas, M. D. A., \& Kurtis, K. E. (2003). Guidelines for the use of lithium to mitigate or prevent ASR. Publication no. FHWA-RD-03-047. McLean, VA: Turner-Fairbank Highway Research Center.

Freitag, S. A., Goguel, R., \& Milestone, N. B. (2003). Alkali silica reaction: Minimising the risk of damage to concrete guidance notes and recommended practice. Technical report. ISSN:1171-4204. Cement \& Concrete Association of New Zealand (CCANZ).

Hooton, R. D. (1995). Test procedures for ASR. In Proceedings of the third annual ICAR symposium: Concrete, bases, and fines. Austin, TX: Center for Aggregates Research. http://aftre.nssga.org/Symposium/1995-31.pdf.

Hooton, R. D., \& Rogers, C. A. (1993). Development of the NBRI rapid mortar bar test leading to its use in North America. Construction and Building Materials, 7(3), 145-148.

Hudec, P., \& Banahene, N. (1993). Chemical treatment and additives for controlling alkali reactivity. Cement \& Concrete Composites, 15, 21-26.

Islam, M. S. (2010). Performance of Nevada's aggregates in alkali-aggregate reactivity of Portland cement concrete. Doctoral dissertation. Las Vegas, NV: University of Nevada.

Islam, M. S., \& Akhtar, S. (2013). A critical assessment to the performance of alkali-silica reaction (ASR) in concrete. Canadian Chemical Transactions, 2(4), 253-266.

Islam, M., \& Ghafoori, N. (2013). Evaluation of alkali-silica reactivity using aggregate geology, mortar bars, concrete prisms and ASR kinetic model. Journal of Materials Science Research, 2(2), 103-117.

Johnston, D., Stokes, D., \& Surdahl, R. (2002). Construction of lithium/fly ash concrete pavement test sections in interstate 90 in SD. TRB annual meeting CD-ROM.

Lane, D. S. (2002). Laboratory investigation of lithium-bearing compounds for use in concrete. Report no. VTRC 02-R16. Charlottesville, VA: Virginia Transportation Research Council.

Li, X. (2005). Mitigating alkali silica reaction in recycled concrete. Ph.D. dissertation, Department of Civil Engineering, University of New Hampshire, Durham, NH.

Malvar, J., Cline, G. D., Burke, D., Rollings, R., Sherman, T., \& Greene, J. (2001). Alkali-silica reaction mitigation state-ofthe-art. Technical report no. TR-2195-SHR. Washington Navy Yard, DC: Naval Facilities Engineering Service Center.

Malvar, J., \& Lenke, L. R. (2006). Efficiency of fly ash in mitigating alkali-silica reaction based on chemical composition. ACI Materials Journal, 103(5), 319-326. 
McCoy, W. J., \& Caldwell, A. G. (1951). A new approach to inhibiting alkali-aggregate expansion. Journal of the American Concrete Institute, 47, 693-706.

McKeen, R. G., Lenke, L. R., \& Pallachulla, K. K. (1998). Mitigation of alkali-silica reactivity in New Mexico. Work performed for New Mexico State Highway and Transportation Department, Materials Research Center, ATR Institute, University of New Mexico, Albuquerque, NM.

Millard, M. J., \& Kurtis, K. E. (2008). Effects of lithium nitrate admixture on early-age cement hydration. Cement and Concrete Research, 38(4), 500-510.

Ramyar, K., Çopuroğlu, O., Andiç, Ö., \& Fraaij, A. L. A. (2004). Comparison of alkali-silica reaction products of fly ash of lithium salt bearing mortar under long-term accelerated curing. Cement and Concrete Research, 34, 1179-1183.

Shehata, M. H., \& Thomas, M. D. A. (2000). The effect of fly ash composition on the expansion of concrete due to alkali-silica reaction. Cement and Concrete Research, 30, 1063-1072.
Stanton, T. E. (1940). Expansion of concrete through reaction between cement and aggregate. Proceedings of the American Society of Civil Engineers, 66(10), 1781-1811.

Stark, D., Morgan, B., Okamoto, P., \& Diamond, S. (1993). Eliminating or minimizing alkali-silica reactivity. Strategic Highway Research Program, SHRP-P-343, Washington, DC.

Taha, B., \& Nounu, G. (2008). Using lithium nitrate and pozzolanic glass powder in concrete as ASR suppressors. Cement \& Concrete Composites, 30, 497-505.

Touma, E. W., Fowler, D. W., \& Carrasquillo, R. L. (2001). Alkali-silica reaction in Portland cement concrete: Testing methods alternatives. Research report ICAR-301-1f. International Center for Aggregates Research (ICAR).

Tremblay, C., Berube, M. A., Fournier, B., Thomas, M. D. A., \& Folliard, K. J. (2007). Effectiveness of lithium-based products in concrete made with Canadian natural aggregates susceptible to alkali-silica reactivity. ACI Materials Journal, 104(2), 195-205. 